\title{
PESAN RASISME DALAM EPISODE THE VINYARDS PADA FILM AMERICAN HISTORY X
}

\author{
Sri Seti Indriani ${ }^{1}$, Evi Rosfiantika ${ }^{1}$ \\ ${ }^{1}$ Universitas Padjadjaran
}

\begin{abstract}
ABSTRAK
Film berlatarbelakang rasisme yang menekankan anti-rasisme sepertinya menjadi tren di perfilman Hollywood. Filmfilm tersebut sebagai media informasi ini mendemonstrasikan perubahan masyarakat yang rasisme menjadi 'postrasisme' American History X merupakan salah satu film yang berupaya menekankan anti-rasis. Film tersebut menceritakan bagaimana kebencian seseorang terhadap perbedaan ras dapat menjadi suatu masalah besar bahkan menghancurkan sebuah keluarga. Fokus penelitian ini bertujuan untuk melihat penanda sebagai petanda pesan rasisme pada salah satu episode dalam film American History X. Penelitian ini merupakan penelitian deskriptif dengan pendekatan semiotika dalam menemukan penanda dan petanda pesan rasisme yang ada pada episode "The Vinyards" pada film American History $X$. Subjek analisis dalam penelitian ini merupakan komunikasi verbal dan nonverbal yang berupa dialog dan narasi gambar pada episode tersebut. Hasil penelitian mengungkapkan bahwa penanda sebagai petanda pesan rasisme pada episode "The Vinyards" dalam film American History X dilihat dari penggunaan komunikasi verbal dan nonverba yang meniputi (1) bahasa tubuh, (2) bahasa verbal, (3) bahasa non-verbal yang dilakukan berupa kekerasan yang terjadi, (4) intonasi suara, (5) teknik pengambilan gambar, dan (6) sudut pandang pengambilan gambar.
\end{abstract}

Kata-kata Kunci: Film, Semiotika, Pesan Rasisme, American History X.

\section{RACISME MESSAGE IN THE EPISODE OF THE VINEYARDS ON AMERICAN HISTORY X FILM}

\begin{abstract}
The film that emphasizes anti-racism seems to become a trend in Hollywood films. These films as a media of information demonstrate the change of the society from racism to 'post-racism'. American History X is one of the films which emphasized anti-racism. The film tells how a person's hatred of racial differences can be problematic and can even destruct a coherence of one family. The focus of this study aims to see the signifier and the signified message of racism in one episode of the film American History X. This research is a descriptive study with a semiotic approach in finding signifiers and signified racism messages in the episode of "The Vinyards" in the film American History X. The subject analysis in this study is the verbal and nonverbal communication form from the dialogue and image narration in the episode mentioned. The results of the study revealed that the signs of racism message in the episode of "The Vinyards" in the film American History X included are: (1) body language, (2) verbal language, (3) nonverbal language through forms of violence, (4) intonation of voice, (5) shooting techniques, and (6) shooting angels.
\end{abstract}

Keywords: Film, Semiotics, Message of Racism, American History X.

Korespondensi: Sri Seti Indriani. Universitas Padjadjaran, Jl. Raya Bandung-Sumedang KM. 21. Email: rahadianindri@gmail.com 
PADA FILM AMERICAN HISTORY $X$

\section{PENDAHULUAN}

Film sebagai media yang sekaligus sebagai media hiburan dan media informasi memiliki tren dengan mengangkat tema filmfilm "magical negro". Film-film tersebut menekankan karakter-karakter kulit hitam yang awalnya merupakan kelas rendah dan tidak berpendidikan bertranformasi menjadi karakter-karakter yang kompeten (Hughey, 2014). Film-film tersebut memberikan semacam dogma bahwa adanya perubahan masyarakat yang awalnya berperilaku rasis menjadi tidak rasis. Hughey (2011) mengatakan bahwa para peninjau film tergantung pada kerangka budaya tertentu untuk mempertandingkan dan mereproduksi gagasan masyarakat "pasca-rasial”.

Film yang memiliki pesan-pesan rasisme di Amerika dan berupaya mengubah pola pikir untuk tidak bersikap rasisme beberapa diantaranya adalah 'The Help', film garapan Tate Taylor merupakan film mengenai sejarah rasisme Amerika. Sejarah Amerika yang sarat dengan perbedaan warna kulit, khususnya mereka yang berkulit putih dan mereka yang berkulit hitam. Film tersebut memperlihatkan bagaimana orang kulit putih ditunjukkan sebagai tuan dan orang kulit putih sebagai pembantu.

Film "Hotel Rwanda" (2004) garapan Terry George menceritakan kisah tentang pembantaian Suku Kutsu. Sementara film yang

\footnotetext{
${ }^{1}$ Film Australia dibuat tahun 1992 dan disutradarai oleh Geoffrey Wright . Film ini menceritakan kebrutalan kelompok neo-Nazi skinhead di Melbourne, film ini
} mengisahkan pengaruh kuat rasisme adalah Romper Stomper ${ }^{l}$ yang menayangkan kebrutalan kelompok neo-Nazi skinhead di Melbourne, Australia.

Film ”Crash" (2004) film garapan Paul Haggis, "Crash" yang memenangkan award mencoba mengupas segi kehidupan sosial Amerika yang sering terjadi di masyarakat Amerika. Film lainnya yang bertemakan sama adalah film 12 years a slave (2013), Django (2012), Freedom Writers (2007), The Butler (2013) dan sebagainya.

Finley dan Finley (2007) menganalisis tiga film anti rasis di tahun 1990-an yaitu; American History X, A Time to kill dan High Learning. Ketiga film tersebut berupaya menunjukkan bahwa kebencan karena perbedaan ras merupakan sebuah masalah. Film 'American History X' merupakan sebuah film yang memiliki latarbelakang rasis. Film ini mendemonstrasikan bagaimana berharganya semangat seorang manusia dan bagaimana seseorang dapat dibujuk untuk mempercayai sesuatu. Film yang salah satu fungsinya sebagai media informasi memberikan pengetahuan bagaimana rasisme dengan mudah dapat merusak sebuah keluarga.

Rasisme pada film bukan hal yang baru, film-film yang bertemakan rasisme sebagian besar disengaja untuk mengubah pola pikir masyarakat. Film-film tersebut berupaya menekankan menjadi orang yang hidup dengan

dibintangi oleh actor laga Russel Crow. Daniel Pollock, Jacqueline McKenzie dan Tony Lee. 
penuh kebencian karena berperilaku rasis akan merusak kehidupannya sendiri. American History $X$ ini mengangkat kenyataan yang hingga hari ini rasisme masih menjadi polemik di negeri paman Sam ini. Film ini memiliki tujuan mengubah perilaku rasisme menjadi tidak. Fokus penelitian ini bertujuan untuk melihat penanda sebagai petanda pesan rasisme pada salah satu episode dalam film American History $X$.

\section{METODE PENELITIAN}

Penelitian ini merupakan penelitian deskriptif dengan pendekatan semiotika dalam menemukan penanda dan petanda pesan rasisme yang ada pada episode "The Vinyards" pada film American History X. Subjek analisis dalam penelitian ini merupakan komunikasi verbal dan nonverbal yang berupa dialog yang pada episode tersebut.

Dalam penelitian ini, peneliti mengumpulkan data primer dan data sekunder. Data primer merupakan dialog berupa komunikasi verbal dan nonverbal yang ada pada episode "The Vinyards" pada film American History $X$. Sedangkan untuk data sekunder, peneliti melakukan studi literatur dengan mencari referensi melalui literatur-literatur baik dari buku, jurnal dokumen, maupun sumbersumber lain yang terkait dengan teks dalam film serta topik lain yang relevan dengan penelitian ini.

\section{Semiotika}

Semiotika berasal dari kata yunani Semeion, yang berarti tanda. Semiotika adalah sebuah cabang ilmu pengetahuan yang mempelajari tentang tanda. Tanda-tanda tersebut menyampaikan suatu informasi atau pesan baik secara verbal/nonverbal sehingga bersifat komunikatif, hal tersebut memunculkan suatu proses pemaknaan oleh penerima tanda akan makna informasi atau pesan dari pengirim pesan. Pierce mengatakan bahwa manusia hanya dapat berpikir dengan medium tanda, manusia hanya dapat berkomunikasi lewat sarana tanda. Tanda-tanda yang dimaksuid Pierce disini berupa isyarat/ tanda gerak, verbal/bunyi dan non-verbal/ bahasa tubuh.

Hubungan antara penanda (signifier) dan petanda (signified) menurut Pierce ini dibagi tiga yaitu (van Zoest, 1996:23):

1. Icon/iconic: a mode in which the signifier is perceived as resembling or imitating the signified (recognizably looking, sounding, feeling, tasting or smelling like it) - being similar in possessing some of its qualities: e.g. a portrait, a cartoon, a scale-model, onomatopoeia, metaphors, 'realistic' sounds in 'programme music', sound effects in radio drama, a dubbed film soundtrack, imitative gestures; Ikon adalah tanda yang memunculkan kembali benda atau realitas yang ditandainya, tanda yang hubungan antara penanda dan petandanya bersifat bersamaan bentuk alamiah. Dengan kata lain, ikon adalah hubungan antara tanda dan objek atau acuan yang bersifat kemiripan misalnya foto atau peta.

2. Index/indexical: a mode in which the signifier is not arbitrary but is directly connected in some way (physically or causally) to the signified - this link can be 
PADA FILM AMERICAN HISTORY $X$

observed or inferred: e.g. 'natural signs' (smoke, thunder, footprints, echoes, nonsynthetic odours and flavours), medical symptoms (pain, a rash, pulse-rate), measuring instruments (weathercock, thermometer, clock, spirit-level), 'signals' (a knock on a door, a phone ringing), pointers (a pointing 'index' finger, a directional signpost), recordings (a photograph, a film, video or television shot, an audio-recorded voice), personal 'trademarks' (handwriting, catchphrase) and indexical words ('that', 'this', 'here', 'there'). Indeks adalah tanda yang kehadirannya menunjukkan adanya hubungan yang ditandai, tanda yang menunjukkan adanya hubungan alamiah antara tanda dan petanda yang bersifat kausal atau hubungan sebab akibat, atau tanda yang langsung mengacu pada kenyataan misalnya api adalah indeks dari api.

3. Symbol/symbolic: a mode in which the signifier does not resemble the signified but which is fundamentally arbitrary or purely conventional - so that the relationship must be learnt: e.g. language in general (plus specific languages, alphabetical letters, punctuation marks, words, phrases and sentences), numbers, morse code, traffic lights, national flags; Simbol adalah sebuah tanda di mana hubungan antara signifier dan signified semata-mata adalah masalah konvensi, kesepakatan atau peraturan. Simbol memiliki hubungan asosiatif dengan gagasan atau referensi serta referen atau dunia acuan. simbol adalah tanda yang menunjukkan hubungan alamiah antara penanda dengan petandanya. Hubungan di antaranya bersifat arbitrer, hubungan berdasarkan konvensi masyarakat. Berdasarkan interpretant, tanda (sign, representamen) dibagi atas rheme, dicent sign atau dicisign dan argument. Rheme adalah tanda yang memungkinkan orang menafsirkan berdasarkan pilihan. Dicent sign atau dicisign adalah tanda sesuai dengan kenyataan. Sedangkan argument adalah yang langsung memberikan alasan tentang sesuatu.

Simbol mempunyai tiga sifat, yaitu : arbitrer (manasuka atau selalu berubah-ubah), bermakna ganda, dan abstrak (Wood, 1998:74). Mulyana (2000:85-98) mengatakan bahwa simbol mempunyai beberapa sifat, yaitu : 1) simbol bersifat manasuka atau sewenangwenang, 2) simbol pada dasarnya tidak mempunyai makna; kitalah yang memberikan makna pada simbol, 3) simbol itu bervariasi.

Pertama, simbol bersifat manasuka dan sewenang-wenang. Simbol bersifat manasuka maksudnya simbol tidak selalu tetap. Demikian juga dengan artinya, bisa berubah sesuai dengan perkembangan zaman (Wood, 1998:74). Apa saja bisa dijadikan simbol, bergantung pada kesepakatan bersama. Kata-kata (lisan atau tulisan), isyarat tubuh, makanan dan cara makan, tempat tinggal, jabatan (pekerjaan), olahraga, hobi, peristiwa, hewan, tumbuhan, gedung, alat (artefak), angka, bunyi, waktu dan 
ProTVF, Volume 2, Nomor 1, Maret 2018, Hal. 87-100

sebagainya, semua bisa dijadikan simbol (Mulyana, 2001:85).

Kedua, Simbol pada dasarnya tidak mempunyai makna; kitalah yang memberi makna pada simbol. Makna yang sebenarnya ada pada kepala kita, bukan terletak pada simbol itu sendiri. Kalaupun ada yang mengatakan bahwa kata-kata mempunyai makna, yang ia maksud sebenarnya adalah kata-kata itu mendorong orang untuk memberi makna (yang telah disetujui bersama) terhadap kata-kata itu (Mulyana, 2001:88).

Ketiga, lambang itu bervariasi. Simbol itu bervariasi dari suatu budaya ke budaya lain, dari suatu tempat ke tempat lain. Begitu juga makna yang diberikan kepada simbol tersebut (Mulyana, 2001:95).

Dari ketiga pengertian simbol diatas, sifat kedua menyatakan bahwa simbol tidak ada artinya sama sekali kecuali manusia itu sendiri yang memaknainya, dan tiap makna yang terdapat dari dalam diri manusia kurang lebih tidak sama cara memaknainya, tergantung pengalaman, dan budaya yang ia telah lampaui.

\section{Pesan Rasisme}

Rasisme merupakan pengertian yang sudah berintegrasi dalam kehidupan sehari-hari. Bila terjadi pembicaraan yang bertema rasisme, umumnya orang mengabaikan perhatian dan pikirannya kepada hal yang lain, bahkan dalam obrolan politik, istilah rasisme sering tanpa disengaja muncul dalam pembicaraan. Sudah banyak film-film produksi hollywood yang mengisahkan problematika rasisme dalam kehidupan, khususnya di negara Amerika (Serikat). Mungkin hal itu disebabkan karena negara ini kaya akan perbedaan ras dengan berbagai warna kulitnya, di mana kelompok penduduk paling menonjol didominasi oleh orang Afrika-Amerika (ras kulit hitam), yaitu mereka yang berasal dari ras suku-bangsa di Afrika yang secara historik melalui era perbudakan sudah turun-temurun tinggal dan berwarganegara Amerika. Sementara itu kelompok penduduk minoritas adalah orang Asia-Amerika (ras kulit berwarna lain), seperti Cina, Jepang, Vietnam dan lain-lainnya yang tersingkir/berimigrasi dan tinggal/menjadi warga Amerika Serikat. Namun munculnya rasisme tiada lain karena sebagian besar penduduk negara Amerika Serikat adalah kelompok penduduk berkulit putih (ras kulit putih) yang berimigrasi dari negara-negara Eropa.

Pesan adalah dalam sebuah teks yang diamati melalui tanda-tanda (signs). Dengan tanda tersebut, kita dapat mengetahui pesanpesan ekspresi emosi dan kognisi si pembuat teks atau pembuat pesan itu, baik secara denotatif maupun konotatif bahkan mitologis (Manning and Swan, 1994 dalam Sudibyo, Hamid dan Qodari, 2001).

Pesan yang terdapat dalam film memberikan efek pada audiens, baik pesan tersebut besifat linguistik maupun non-verbal. Pesan linguistik terbagi lagii dalam dua kategori, yakni pesan paralinguistik, yakni manusia menggucapkan kata-kata dan kalimat dengan cara-cara tertentu, serta pesan ekstralinguistik yaitu manusia menyampaikan pesan dengan cara-cara lain selain bahasa misalnya dengan isyarat-isyarat tertentu yang 
telah disepakati maknanya seblumnya oleh anggota masyarakat tersebut.

Selain pesan linguistik yang sangat penting untuk ditelaah dalam menangkap pesan yang terdapat dalam film, pesan non-verbal turut memiliki kepentingan yang sama.

Seperti yang dinyatakan Mark L. Knapp(1972:9-12) (dalam Jaluddin Rakhmat), pesan non verbal memiliki lima fungsi yaitu:

1. Repetisi, mengulang gagasan yang sudah disajikan secara verbal.

2. Substitusi, menggantikan lambanglambang verbal

3. Kontradiksi, menolak pesan verbal atau memberikan makna yang lain terhadap pesan verbal

4. Komplemen, melengkapi dan memperkaya makna pesan non verbal

5. Aksentuasi, menegaskan pesan verbal atau mengaris bawahinya.

\section{HASIL DAN PEMBAHASAN}

Film American History $X$ merupakan sebuah film panjang berdurasi satu jam 59 menit dan bergenre kiminal drama. Film ini di tulis oleh David McKenna dan disutradarai oleh Tony Kaye. Film ini di keluarkan pada tanggal 20 November 1998. Film yang banyak mengisyaratkan pesan rasisme pada khalayak mengingatkan kembali pada kebrutalan Nazi Hitler pada perang dunia ke II. Film ini memberikan gambaran bagaimana suatu kehidupan bisa rusak hanya karena rasa 'benci' kepada manusia lain yang memiliki ras yang berbeda.
PADA FILM AMERICAN HISTORY $X$ Inti dari cerita film American History $X$ ini menceritakan seorang Neo-Nazi skinhead, Derek yang diperankan oleh Edward Norton, dipenjara setelah membunuh dua pemuda kulit hitam yang mencoba mencuri mobil ayahnya. Setelah mendekam di penjara cukup lama, ia menyadari kesalahannya dan tidak lagi bangga dengan kekuatan kulit putih. Setelah pada akhirnya Derek dibebaskan dari penjara, ia melihat adiknya, Danny yang diperankan oleh Edward Furlong mengikuti jejaknya dalam membenci semua ras non kulit hitam. Derek kemudian mencoba mengubah perilaku adiknya dan memberinya penjelasan bahwa kehidupan yang penuh kebencian bukanlah sebuah kehidupan. Namun, ketika Danny pada akhirnya memahami kakaknya, semua sudah terlambat. Danny ditembak mati di kamar mandi oleh seorang remaja kulit hitam.

Penelitian ini fokus pada sebuah episode dalam film American History $X$ yang bertema "The Vinyards". "The Vinyards" merupakan nama keluarga Derek dan Danny. Berikut adalah penjelasan singkat cerita dalam episode tersebut dan bagaimana kandungan pesanan rasisme terlihat pada penanda-penanda:

"The Vinyards", episode ini banyak sekali memberikan penanda-penanda sebagai isyarat adanya pesan-pesan rasis. Yang terjadi dalam adegan ini adalah flash back Danny di masa lalu sehari sebelum terjadinya insiden berdarah. Insiden dimana Derek membunuh dua pemuda kulit hitam. Ia membunuh kedua pemuda ini bukan saja karena kedua pemuda kulit hitam ini mencoba mencuri mobil 
ayahnya, namun ia membunuhnya karena kebenciannya terhadap kaum kulit hitam. Keluarga Vinyard, yakni Doris (Ibunya Derek dan Danny), Danny, Derek, Davina, Stacey (pacar Derek) dan Murray (teman dekat ibu mereka sekaligus dosen sejarah Derek dan Danny disekeloh, yang kebetulan juga merupakan orang keturunan yahudi) sedang menikmati hidangan makan di ruang makan. Mereka terlibat dalam diskusi yang bernuansa rasis. Perdebatan yang sengit tidak dapat dihindari. Banyak keluar tanda-tanda secara verbal. Episode ini akan dijelaskan lebih terperinci dibawah.

Episode "The Vinyards" (keluarga Vinyard)

Episode ini merupakan flash back dari kenangan masa lalu Danny yang digambarkan melalui gambaran hitam putih. Adegan ini menceritakan mengenai beberapa lama setelah wafatnya ayah mereka, Danny meyakinkan dalam tulisannya bahwa apa yang terjadi pada Derek sekarang ini sebenarnya sudah lama dapat diprediksi dan tersirat. Danny menceritakan tentang suatu malam ketika keluarga Vinyard sedang berdiskusi di meja makan saat makan malam. Disana terlihat ada Murray yang ketika itu sedang mendekati ibu mereka Doris. Ada Danny, Davina, Derek dan stacey. Mereka sedang berada di pertengahan diskusi mengenai beberapa aksi teror yang sedang terjadi akhir-akhir ini pada beberapa toko-toko yang dimiliki sebagian besar oleh warga ras kulit hitam. Termaksud membicarakan kejadian yang terjadi di toko
Archie's randy market (yang sebenarnya dipimpin oleh Derek dan remaja-remaja skinhead malam sebelum-sebelumnya). Derek sepertinya sedang meracuni mereka bahwa pelakunya adalah anggota ras kulit hitam pula.

Adapun dialog yang terjadi dibawah ini:

\begin{tabular}{|c|c|c|}
\hline Tokoh & Dialog & $\begin{array}{c}\text { Keterangan } \\
\text { Adegan }\end{array}$ \\
\hline Derek & $\begin{array}{l}\text { Fuck you, Murray. } \\
\text { White men don't cruise } \\
\text { the streets of LA killing } \\
\text { each other } \\
\text { (Bedebah kau Murray. } \\
\text { Bangsa kulit putih tidak } \\
\text { menyebar dijalanan LA } \\
\text { dan saling membunuh) }\end{array}$ & \\
\hline Murray & $\begin{array}{l}\text { No. You guys make } \\
\text { bombs. } \\
\text { (Tidak. Kalian membuat } \\
\text { bom) }\end{array}$ & $\begin{array}{l}\text { Derek stares } \\
\text { at the man, } \\
\text { eyes filled } \\
\text { with } \\
\text { homicide. } \\
\text { Derek } \\
\text { menatap pria } \\
\text { tersebut, } \\
\text { matanya } \\
\text { penuh murka }\end{array}$ \\
\hline Derek & $\begin{array}{l}\text { You're so fucking lame. } \\
\text { A couple of cranks in } \\
\text { cabins in Montana is not } \\
\text { statistically significant. } \\
\text { White Americans don't } \\
\text { take PCP and drink } \\
\text { and drive a hundred and } \\
\text { twenty fuckin' miles an } \\
\text { hour! We pull over and } \\
\text { trust the law. } \\
\text { Kau begitu bodoh. } \\
\text { Beberapa orang yang } \\
\text { berkemah di Montana } \\
\text { tidak memberikan } \\
\text { statistic yang signifikan. } \\
\text { Orang-orang Amerika } \\
\text { kulit putih tidak } \\
\text { menyetir dan mabuk } \\
\text { seratusduapuluh mil } \\
\text { sejam!kami berhenti dan } \\
\text { percaya hukum }\end{array}$ & \\
\hline Murray & $\begin{array}{l}\text { You're kidding, right? } \\
\text { Kau bercanda kan? }\end{array}$ & \\
\hline Davina & $\begin{array}{l}\text { (sarcastically)'Don't } \\
\text { you know, Murray? }\end{array}$ & \\
\hline
\end{tabular}

\footnotetext{
${ }^{2}$ PCP adalah semacam obat-obatan terlarang
} 


\begin{tabular}{|c|c|}
\hline & $\begin{array}{l}\text { White people never } \\
\text { break the law. We're } \\
\text { perfect little angels. } \\
\text { (sarkastik) tidakkah kau } \\
\text { mengetahui, Murray? } \\
\text { Orang kulit putih tidak } \\
\text { pernah melanggar } \\
\text { hukum. Kami adalah } \\
\text { malaikat-malaikat kecil } \\
\text { yang sempurna }\end{array}$ \\
\hline Derek & $\begin{array}{l}\text { That's not what I said, } \\
\text { Davina... Three different } \\
\text { times Rodney King } \\
\text { comes at those officers } \\
\text { with the intent to hurt } \\
\text { them. To hurt them! } \\
\text { Three times! But since } \\
\text { we see it on some } \\
\text { fucking tampered } \\
\text { videotape...the bleeding } \\
\text { heart media makes you } \\
\text { believe that he only } \\
\text { comes at them once. All } \\
\text { we see is Powell, Koon } \\
\text { and Wind hittin' him } \\
\text { and-- (busting up } \\
\text { laughing) Briseno } \\
\text { kickin' him in the back } \\
\text { of the fuckin' skull with } \\
\text { his boot. Still, the } \\
\text { dumbfuck's tryin' to get } \\
\text { up and kick their asses! } \\
\text { That's how stupid that } \\
\text { motherfucker is. Those } \\
\text { cops used textbook-solid } \\
\text { tactics and if Dad were } \\
\text { still here he'd say the } \\
\text { same damn thing”'. } \\
\text { Saya tidak mengatakan } \\
\text { itu Davina tiga kali } \\
\text { dalam waktu yang } \\
\text { berbeda Rodney King } \\
\text { mendatangi para petugas } \\
\text { dengan maksud } \\
\text { menyakiti mereka. } \\
\text { Untuk meyakiti mereka! } \\
\text { Tiga kali! Namun }\end{array}$ \\
\hline
\end{tabular}

\footnotetext{
${ }^{3}$ Rodney King adalah seorang supir taksi turunan AfrikaAmerika yang pada tahun 1991 di hentikan oleh tiga petugas yaitu Laurence Powell, Timothy Wind, Theodore Briseno dan Sergeant Stacey Koon setelah dituduh menyetir mobil taxinya melewati batas kecepatan normal. Namun dakwaan tersebut masih dalam keadaan simpang siur, apakan karena obatobatan terlarang atau alkohol. Ketiga petugas tersebut memukuli Rodney hingga babak belur. Bukti diambil
}

\begin{tabular}{|l|l|l|}
\hline & $\begin{array}{l}\text { karena kita melihatnya } \\
\text { di semacam video } \\
\text { murahan,..media } \\
\text { membuat kita percaya } \\
\text { bahwa ia hanya } \\
\text { mendatangi mereka } \\
\text { sekali. Yang kita lihat } \\
\text { adalah Powell, Koon, } \\
\text { dan Wind memukulinya } \\
\text { dan- (tertawa) Briseno } \\
\text { menendangnya dari } \\
\text { belakang tengkoraknya } \\
\text { dengan boot. Tetap } \\
\text { orang-orang bodoh itu } \\
\text { mencoba untuk } \\
\text { menendangnya! } \\
\text { Begitulah bodohnya } \\
\text { orang itu. Polisi-polisi } \\
\text { itu menggunakan } \\
\text { prosedur dan taktik } \\
\text { berdasarkan buku dan } \\
\text { jika ayah masih ada dia } \\
\text { akan mengatakan hal } \\
\text { yang sama. }\end{array}$ & \\
\hline Derek & $\begin{array}{l}\text { No. Appropriately. } \\
\text { Appropriately! Cops } \\
\text { have been granted a }\end{array}$ & Davina starts \\
to laugh. \\
\hline Derek & $\begin{array}{l}\text { That doesn't make it } \\
\text { right } \\
\text { Itu bukan berarti } \\
\text { menghalalkan segala } \\
\text { sesuatu } \\
\text { They're cops! They are } \\
\text { taught to use that stick } \\
\text { and they did. } \\
\text { Tentu saja betul. Mereka } \\
\text { itu petugas-petugas! } \\
\text { Mereka diajarkan } \\
\text { prosedur itu dan mereka } \\
\text { melakukannya. }\end{array}$ & \\
\hline $\begin{array}{l}\text { Secara berlebihan } \\
\text { Doris }\end{array}$ & \\
\hline
\end{tabular}

dari kamera seorang warga setempat yang secara tidak sengaja menyorot kejadian tersebut. Ketiga petigas tersebut akhirnya dihukum selama 30 bulan penjara. Kejadian ini juga adalah awal dari keributan antar ras yang terjadi pada tahun 1992 di Los Angeles yang memakan korban 55meninggal, 2,383 luka-luka, lebih dari 7,000 tembakan, kerusakan terhadap 3,100 perusahaan, dan hampir $\$ 1$ billion kerugian finansial. 


\begin{tabular}{|c|c|c|}
\hline & $\begin{array}{l}\text { certain amount of } \\
\text { authority by society and } \\
\text { white people, } \\
\text { unfortunately, are the } \\
\text { only ones who } \\
\text { acknowledge it. I } \\
\text { acknowledge a cop's } \\
\text { authority } \\
\text { Tidak, secara tepat! } \\
\text { Secara tepat! Para } \\
\text { petugas telah diberi } \\
\text { semacam wewenang } \\
\text { oleh masyarakat dan } \\
\text { orang-orang kulit putih, } \\
\text { sayangnya, kami hanya } \\
\text { lah beberapa orang yang } \\
\text { mengakuinya. Saya } \\
\text { mengakui kewenangan } \\
\text { para petugas. }\end{array}$ & $\begin{array}{l}\text { Davina mulai } \\
\text { tertawa }\end{array}$ \\
\hline Davina & $\begin{array}{l}\text { Look who's talking } \\
\text { about respecting the } \\
\text { law? Mr. K.K.K. here } \\
\text { Lihat siapa yang } \\
\text { ngomong tentang } \\
\text { menghargai hukum? } \\
\text { Tuan KKK }\end{array}$ & \\
\hline Derek & $\begin{array}{l}\text { That's two errors in one } \\
\text { sentence, Davina, so } \\
\text { take a fucking course in } \\
\text { semantics. First error--I } \\
\text { didn't say I respect the } \\
\text { law. I said I respect a } \\
\text { cop's authority. Second } \\
\text { error...I'm not a member } \\
\text { of the fuckin' low rent, } \\
\text { disorganized, redneck } \\
\text { Ku Klux Klan.. Pull } \\
\text { your head outta your ass } \\
\text { and look at who you're } \\
\text { dealing with } \\
\text { Itu dua kesalahan dalam } \\
\text { satu kalimat, Davina, } \\
\text { jadi ambilah kursus } \\
\text { semiotic. Kesalahan } \\
\text { pertama-saya tidak } \\
\text { bilang saya menghargai } \\
\text { hukum. Saya bilang } \\
\text { saya menghargai } \\
\text { kewenangan para } \\
\text { petugas. Kesalahan } \\
\text { kedua.. saya bukan } \\
\text { anggota dari kelompok } \\
\text { picisan, yang tidak } \\
\text { teratur Ku Klux } \\
\text { Klan..pakailah otakmu } \\
\text { dan lihat kamu } \\
\text { berurusan sama siapa! }\end{array}$ & \\
\hline
\end{tabular}

\begin{tabular}{|c|c|c|}
\hline Murray & $\begin{array}{l}\text { Don't speak to her that } \\
\text { way, Derek } \\
\text { Jangan berbicara seperti } \\
\text { itu pada adikmu Derek. }\end{array}$ & \\
\hline Derek & $\begin{array}{l}\text { True enough. The point } \\
\text { is...if Dan was walking } \\
\text { across the street that } \\
\text { night and Rodney King } \\
\text { plowed into him- } \\
\text { Benar. Intinya...jika } \\
\text { Dan sedang berjalan di } \\
\text { jalanan malam itu dan } \\
\text { Rodney King } \\
\text { membajaknya... }\end{array}$ & \\
\hline Doris & $\begin{array}{l}\text { Can we forget about } \\
\text { Rodney King for } \\
\text { chrissake! } \\
\text { Dapatkah kita } \\
\text { melupakan soal Rodney } \\
\text { king ya Tuhanku! }\end{array}$ & \\
\hline Derek & $\begin{array}{l}\text {--while hopped up on } \\
\text { Chivas and } \\
\text { P.C.P...you'd consider } \\
\text { the force those cops } \\
\text { used to be justified! } \\
\text { - sementara kemudian } \\
\text { menaiki Chivas dan } \\
\text { P.C.P..kamu akan } \\
\text { mempertimbangkan } \\
\text { perilaku petugas- } \\
\text { petugas tersebut untuk } \\
\text { keadilan. }\end{array}$ & \\
\hline Doris & $\begin{array}{l}\text { He didn't hit anybody! } \\
\text { Dia tidak memukuli } \\
\text { siapapun! }\end{array}$ & \\
\hline Derek & $\begin{array}{l}\text { If he did though! If that } \\
\text { shithead killed } \\
\text { Dan...you would have } \\
\text { believed the beating to } \\
\text { be justified and so } \\
\text { would everybody else. } \\
\text { But since he didn't hit } \\
\text { anyone...it's "Hands } \\
\text { Across America" for the } \\
\text { son of a bitch. } \\
\text { Jika dia melakukannya! } \\
\text { Jika orang itu } \\
\text { membunuh Dan..kamu } \\
\text { akan percaya bahwa } \\
\text { pemukulan harus } \\
\text { dibenarkan dan semua } \\
\text { orang juga. Namun, } \\
\text { karena dia tidak } \\
\text { memukul siapa pun, kita } \\
\text { mana tau }\end{array}$ & $\begin{array}{l}\text { Derek takes a } \\
\text { bite of food. } \\
\text { Derek } \\
\text { memakan } \\
\text { makanannya }\end{array}$ \\
\hline & $\begin{array}{l}\text { We are still so hung up } \\
\text { in this notion that we }\end{array}$ & \\
\hline
\end{tabular}


PADA FILM AMERICAN HISTORY $X$

\begin{tabular}{|c|c|c|}
\hline & $\begin{array}{l}\text { have an obligation to } \\
\text { help the struggling } \\
\text { black man and all you } \\
\text { contribute to it! Lincoln } \\
\text { freed the slaves a } \\
\text { hundred and thirty years } \\
\text { ago,how many more } \\
\text { years do we need to act! } \\
\text { Kita semua begitu } \\
\text { takjub pada dugaan itu } \\
\text { sehingga sepertinya kita } \\
\text { memiliki kewajiban } \\
\text { untuk membantu } \\
\text { perjuangan orang-orang } \\
\text { kulit hitam dan kamu } \\
\text { semu berkontribusi akan } \\
\text { hal ini! Lincoln } \\
\text { membebaskan para } \\
\text { budak seratus tigapuluh } \\
\text { tahun yang lalu! }\end{array}$ & \\
\hline Stacey & $\begin{array}{l}\text { I'm with you, honey. All } \\
\text { the way. It's } \\
\text { one...giant...ploy } \\
\text { Saya bersamamu, } \\
\text { sayang. Sepanjang jalan. } \\
\text { Ini semua satu } \\
\text { permainan bersama }\end{array}$ & \\
\hline Davina & $\begin{array}{l}\text { Here we go } \\
\text { Mulai lagi kita... }\end{array}$ & \\
\hline Stacey & $\begin{array}{l}\text { I mean...nobody likes } \\
\text { Chief whatever his name } \\
\text { is, right? } \\
\text { Maksudku...tidak } \\
\text { adseorangpun yang } \\
\text { menyukai ... siapapun } \\
\text { namanya, betulkan? }\end{array}$ & \\
\hline Davina & Gates & \\
\hline Stacey & $\begin{array}{l}\text { Yeah. So here comes } \\
\text { this filthy piece of } \\
\text { garbage in his Hyundai. } \\
\text { He pulls over in front of } \\
\text { a perfectly lighted area } \\
\text { where a video camera is } \\
\text { sitting there...fucking } \\
\text { waiting for him, man. } \\
\text { What happens next? } \\
\text { Chief Gates is dust. It's } \\
\text { total-Ya. Jadi } \\
\text { datanglah sebongkah } \\
\text { rongsokan dalam } \\
\text { Hyundainya. Dia } \\
\text { berhenti tepat didepan } \\
\text { area yang penuh sorotan } \\
\text { lampu yang terang, }\end{array}$ & $\begin{array}{l}\text { Davina drops } \\
\text { her } \\
\text { silverware on } \\
\text { the plate with } \\
\text { a clatter and } \\
\text { looks at her } \\
\text { mother. } \\
\text { Everyone } \\
\text { stares at } \\
\text { Davina. } \\
\text { Davina } \\
\text { menjatuhkan } \\
\text { alat } \\
\text { makannya di } \\
\text { atas piring } \\
\text { dan melihat } \\
\text { ibunya. }\end{array}$ \\
\hline
\end{tabular}

yangmana sebuah

kamera

ada..menunggunya. apa

yang terjadi? Gates

menjadi debu. Semua...

Semua orang

melihat

Davina

\section{Percakapan mereka pun berakhir dengan}

perkelahian antara Derek dan Davina, karena Derek tidak bisa menerima Davina yang ingin meninggalkan meja makan ketika pacarnya Stacey sedang memberikan opininya. Derek memberinya pelajaran, dan memaksa davina untuk meminta maaf pada pacarnya. Ketika itu Derek menjambak rambut Davina dan menyumpal mulut Davina dengan makanan yang ada dia tas meja makan.

\begin{tabular}{|l|l|l|}
\hline Murray & $\begin{array}{l}\text { She can't breath } \\
\text { Dia tidak dapat } \\
\text { bernafas! }\end{array}$ & \\
\hline Dorris & $\begin{array}{l}\text { Let her go! } \\
\text { Lepaskan dia! }\end{array}$ & \\
\hline Davina & $\begin{array}{l}\text { I hate you! } \\
\text { Saya benci kamu! }\end{array}$ \\
\hline
\end{tabular}

Ketika Danny dan doris hendak menghentikan apa yang tengah dilakukan Derek terhadap davina, mereka secara tidak sengaja tersungkir dan jatuh ke lantai. Davina lari ke menuju kamarnaya sambil menangis. Murray pun angkat bicara, dan ketika itu pun keadaannya pun tambah diluar kendali. Derek memberikan komentar pada murray, yang kurang lebih sangat deskriminatif, karena Murray sendiri adalah turunan orang yahudi.

\begin{tabular}{|c|c|c|}
\hline Murray & $\begin{array}{l}\text { What are you doing? } \\
\text { This is your family }\end{array}$ & \\
\hline Derek & $\begin{array}{l}\text { Right. My family, so you } \\
\text { know what? I don't give } \\
\text { two shits about you or } \\
\text { what you think. You're } \\
\text { not part of it. } \\
\text { Betul. Keluarga saya, } \\
\text { jadi apakah kau tau? } \\
\text { Saya tidak peduli } \\
\text { tentang dirimu atau } \\
\text { opini kamu. Kamu } \\
\text { bukan bagian dari ini } \\
\text { semua }\end{array}$ & \\
\hline Murray & $\begin{array}{l}\text { That has nothing to do } \\
\text { with it. } \\
\text { Ini tidak ada } \\
\text { hubungannya }\end{array}$ & \\
\hline Derek & $\begin{array}{l}\text { it doesn't? you don't } \\
\text { think I see what you're } \\
\text { doing? You think I'll sit } \\
\text { here and smile while } \\
\text { some fucking kike tries } \\
\text { to fuck my mother? It's } \\
\text { never going to happen. } \\
\text { Fucking forget it. Not }\end{array}$ & $\begin{array}{l}\text { Murray } \\
\text { melihat } \\
\text { Derek dengan } \\
\text { wajah putius } \\
\text { asa dan sedih } \\
\text { dan perlahan- } \\
\text { lahan } \\
\text { meninggalkan }\end{array}$ \\
\hline
\end{tabular}




\begin{tabular}{|c|c|c|}
\hline & $\begin{array}{l}\text { while I'm in this family. } \\
\text { I will fucking cut your } \\
\text { shylock nose off before I } \\
\text { let that happen. Coming } \\
\text { in here and poisoning } \\
\text { my family's dinner with } \\
\text { your jewish, nigger- } \\
\text { loving, hippie bullshit } \\
\text { Tidak? Kau kira saya } \\
\text { tidak melihat apa yang } \\
\text { sedang kau lakukan? } \\
\text { Kau pikir saya akan } \\
\text { terdiam dan tersenyum } \\
\text { sementara seorang } \\
\text { yahudi berusaha } \\
\text { mendekati ibuku? Tidak } \\
\text { akan pernah terjadi. } \\
\text { Lupakanlah. Tidak akan, } \\
\text { selama aku berada di } \\
\text { dalam keluarga ini! } \\
\text { Saya akan memotong } \\
\text { hidungmu yang besar itu } \\
\text { sebelum semuanya } \\
\text { terjadi. Datang kesini } \\
\text { dan meracuni makan } \\
\text { malam keluargaku } \\
\text { dengan yahudimu, } \\
\text { kecintaan terhadap } \\
\text { orang kulit hitam, dan } \\
\text { omong kosong hippie! }\end{array}$ & $\begin{array}{l}\text { meja makan } \\
\text { menuju pintu } \\
\text { depan }\end{array}$ \\
\hline & $\begin{array}{l}\text { Fuck you! Yeah.. walk } \\
\text { out! asshole fucking } \\
\text { cabala reading } \\
\text { motherfucker. Get out of } \\
\text { my house!! } \\
\text { Brengsek! } \\
\text { Tah..lari!(Sumpah } \\
\text { serapah) pergi dari } \\
\text { rumahku! }\end{array}$ & $\begin{array}{l}\text { Sebelum } \\
\text { Murray } \\
\text { membuka } \\
\text { pintu depan, } \\
\text { ia menoleh } \\
\text { kembali ke } \\
\text { arah Derek }\end{array}$ \\
\hline & $\begin{array}{l}\text { You see this? That } \\
\text { means not welcome!!! } \\
\text { Kau lihat ini? Artinya } \\
\text { Tidak diinginkan! }\end{array}$ & $\begin{array}{l}\text { Derek } \\
\text { menunjukkan } \\
\text { jari } \\
\text { tengahnya } \\
\text { pada Murray }\end{array}$ \\
\hline Doris & $\begin{array}{l}\text { You know...sometimes } \\
\text { it's hard to believe I } \\
\text { gave birth to you } \\
\text { kau tau..kadang-kadang } \\
\text { susah percaya bahwa } \\
\text { saya melahirkanmu }\end{array}$ & \\
\hline Derek & $\begin{array}{l}\text { Give thanks to the food } \\
\text { on the table and then } \\
\text { believe it, Doris." } \\
\text { Terimakasih atas } \\
\text { makanan diatas meja } \\
\text { dan percayalah, Doris }\end{array}$ & \\
\hline Doris & $\begin{array}{l}\text { We both put food on this } \\
\text { table, fella }\end{array}$ & \\
\hline
\end{tabular}

\section{Petanda dan Penanda Pesan Linguistik Terkodekan dan Tak Terkodekan}

\begin{tabular}{|c|c|}
\hline Petanda (Signifier) & Penanda (Signified) \\
\hline $\begin{array}{l}\text { White men don't cruise } \\
\text { the streets of LA killing } \\
\text { each other."--ras kulit } \\
\text { putih tidak menjelajahi } \\
\text { jalanan dan saling } \\
\text { menembak antar } \\
\text { sesama-- }\end{array}$ & $\begin{array}{l}\text { Derek ingin meyakinkan } \\
\text { semua orang di meja } \\
\text { makan bahwa kegiatan } \\
\text { saling membunuh di } \\
\text { beberapa area Los } \\
\text { Angelas adalah budaya } \\
\text { yang dilakukan oleh ras } \\
\text { kulit hitam. Derek ingin } \\
\text { memberi pengertian } \\
\text { bahwa orang kulit putih } \\
\text { memilki sifat barbarian, } \\
\text { seperti binatang, yang } \\
\text { kerjanya hanya } \\
\text { berdasarkan insting, } \\
\text { saling membunuh. } \\
\text { Berbeda dengan ras kulit } \\
\text { putih yang terlihat lebih } \\
\text { beradab }\end{array}$ \\
\hline $\begin{array}{l}\text { "Look who's talking } \\
\text { about respecting the } \\
\text { law? Mr. K.K.K. } \\
\text { here".--Lihat siapa } \\
\text { yang ngomong tentang } \\
\text { menghargai hukum? } \\
\text { Tuan KKK-- }\end{array}$ & $\begin{array}{l}\text { Davina ingin menyindir } \\
\text { Derek yang berlagak } \\
\text { seperti malaikat, yang } \\
\text { sealu mematuhi peraturan } \\
\text { hukum, padahal dirinya } \\
\text { berlagak arphatheid, } \\
\text { seperti yang dianut oleh } \\
\text { kelompok KKK. }\end{array}$ \\
\hline $\begin{array}{l}\text { "We are still so hung } \\
\text { up in this notion that we } \\
\text { have an obligation to } \\
\text { help the struggling } \\
\text { black man and all you } \\
\text { contribute to it! Lincoln } \\
\text { freed the slaves a } \\
\text { hundred and thirty } \\
\text { years ago, how many } \\
\text { more years do we need } \\
\text { to act!” --Kita semua } \\
\text { begitu takjub pada } \\
\text { dugaan itu sehingga } \\
\text { sepertinya kita memiliki } \\
\text { kewajiban untuk } \\
\text { membantu perjuangan } \\
\text { orang-orang kulit hitam } \\
\text { dan kamu semu } \\
\text { berkontribusi akan hal } \\
\text { ini! Lincoln } \\
\text { membebaskan para } \\
\text { budak seratus tigapuluh } \\
\text { tahun yang lalu! }\end{array}$ & $\begin{array}{l}\text { Derek dengan intonasi } \\
\text { bicara yang semangat } \\
\text { berkobar-kobar dan } \\
\text { seperti tidak ada titik dan } \\
\text { koma ingin menyatakan } \\
\text { bahwa seharusnya warga } \\
\text { masyarakat beraksi untuk } \\
\text { merebut kembali hak- } \\
\text { haknya dan menghentikan } \\
\text { ras kulit hitam yang } \\
\text { lamban laun merajalela } \\
\text { dimana-mana dan } \\
\text { mengusai tempat-tempat } \\
\text { yang dulunya adalah milik } \\
\text { ras kulit putih. }\end{array}$ \\
\hline
\end{tabular}


PADA FILM AMERICAN HISTORY $X$

\begin{tabular}{|c|c|}
\hline $\begin{array}{l}\text { You think I'll sit here } \\
\text { and smile while some } \\
\text { fucking kike tries to fuck } \\
\text { my mother?-- Kau pikir } \\
\text { saya akan terdiam dan } \\
\text { tersenyum sementara } \\
\text { seorang yahudi } \\
\text { berusaha mendekati } \\
\text { ibuku?-- }\end{array}$ & $\begin{array}{l}\text { Derek ingin menghina } \\
\text { Murray dengan perkataan } \\
\text { kike, karena kata tersebut } \\
\text { merupakan hinaan bagi } \\
\text { orang-orang yang ingin } \\
\text { menghina orang yahudi, } \\
\text { seperti layaknya nigger } \\
\text { yang dipakai untuk } \\
\text { mengina orang negro. } \\
\text { Kedua kata tersebut } \\
\text { sangat menyakitkan untuk } \\
\text { keua ras. }\end{array}$ \\
\hline $\begin{array}{l}\text { Coming in here and } \\
\text { poisoning my family's } \\
\text { dinner with your jewish, } \\
\text { nigger-loving, hippie } \\
\text { bullshit--datang kesini } \\
\text { dan meracuni makan } \\
\text { malam keluargaku } \\
\text { dengan yahudimu, } \\
\text { kecintaan terhadap } \\
\text { orang negro, dan omong } \\
\text { kosong hippie! }\end{array}$ & $\begin{array}{l}\text { Derek ingin menyatakan } \\
\text { bahwa apa yang dibawa } \\
\text { Murray ke dalam } \\
\text { keluarganya sama sekali } \\
\text { tidak diterima, dan } \\
\text { dianggap meracuni } \\
\text { mereka. Apapun yang } \\
\text { bukan berasal dari ras } \\
\text { kulit putih itu salah. }\end{array}$ \\
\hline $\begin{array}{l}\text { You see this? That } \\
\text { means not welcome!!!-- } \\
\text { Kau lihat ini? Artinya } \\
\text { Tidak diinginkan!- }\end{array}$ & $\begin{array}{l}\text { Derek ingin } \\
\text { memperlihatkan sesuatu } \\
\text { pada Murray, apapun } \\
\text { yang ditujukkannya pada } \\
\text { Murray tersebut berarti } \\
\text { tidak disambut dengan } \\
\text { baik. Maksudnya, Murray } \\
\text { tidak diinginkan, tidak } \\
\text { diterima di area } \\
\text { lingkungan Derek dan } \\
\text { tidak akan pernah. Makna } \\
\text { tersebut diyakinkan } \\
\text { dengan intonasi suara } \\
\text { Derek yang sangat tinggi } \\
\text { dan mengebu-gebu. }\end{array}$ \\
\hline
\end{tabular}

Teknik pengambilan gambar pada episode "The Vinyards" sebagian besar menggunakan teknik Close up (dekat) untuk menunjukkan pentingnya suatu objek. Hal ini ditunjukkan ketika Derk berbicara dengan semangat, dan teknik pengambilannya dekat. Pengambilan gambar tersebut untuk menekankan pentingnya inti cerita dalam episode tersebut. Medium shot juga dilakukan ntuk menggambarkan pengenalan suatu objek dan Long shot untuk menunjukkan hubungan antara subjek dan latar belakang. Pada pengambilan gambar long shot diperlihatkan bahwa episode "the Vinyards" berada di ruang makan malam, secara budaya. Latar belakang ruang makan memperlihatkan bahwa keributan yang terjadi dilakukan di ruang makan tempat yang seharusnya merupakan tempat bercerita dengan nyaman dan bernuansa kekeluargaan. Namun, menjadi kontradiksi melihat akhir episode ditutup dengan Murray yang pergi meninggalkan rumah Derek, sedangkan derek sedang mencaci makinya. Hal ini menimbulkan kesan tidak nyaman bagi penonton yang melihatnya.

Sudut pandang pengambilan gambar (angle), yang sering digunakan adalah: Low angle (untuk menunjukkan sifat kekuasaan), High angle (untuk menunjukkan kebalikan dari low angle) dan eye level (untuk menunujukan kesejajaran atau netral). Ini dapat dilihat ketika Derek sedang berbicara dengan anggota keluarganya ketika bersikeras terhadap pendapatnya.

Hasil analisa diatas menunjukkan bahwa tanda dan penanda baik berupa pesan verbal maupun nonverbal (ikonik dan linguistik) saling berkaitan satu dengan lainnya tanpa mengabaikan salah satunya dalam menciptakan pesan-pesan yang ada dalam film. Van Zoest (van Zoest, 1993:109, dalam Alex Sobur) mengatakan bahwa film dibangun dengan tanda semata-mata. Tanda-tanda itu termaksud berbagai sistem tanda yang bekerja sama dengan baik untuk mencapai efek yang diharapkan. Film menciptakan imajinasi dan sistem penandaan. Karena itu menurut van 
Zoest, bersamaan dengan tanda-tanda aristektur, terutama indeksikal, pada film terutama diggunakan tanda-tanda ikonis, yakni tanda-tanda yang menggambarkan sesuatu. Gambar film adalah persamaannya dengan realitas yang ditunjukkan. Gambar yang dinamis dalam film merupakan ikonis bagi realitas yang dinotasikannya.(van Zoest 1993:109).

\section{SIMPULAN}

Ciri-ciri yang digunakan dalam mengelola petanda dan penalam episode "The Vinyards" pada film American History $X$ dalam memberikan pesan rasis adalah sebagai berikut:

1. Bahasa tubuh (Gesture) dan ekspresi wajah seperti kemarahan yang diperlihatkan menandakan kebencian. Kebencian yang ditunjukkan melalui tatapan sinis, atau mata melotot.

2. Bahasa verbal yang mengandung banyak cacian dan makian terhadap beberapa orangorang Afrika-Amerika dan pada Murray yang merupakan turunan yahudi yang dengan sengaja dilontarkan.

3. Bahasa non-verbal yang dilakukan berupa kekerasan yang terjadi. Kekerasan yang seolah-olah di halalkan karena kebencian rasis tersebut.

4. Lambang-lambang seperti swastika, simbolsimbol nazi lainnya yang ada pada bagian tubuh Derek.

5. Intonasi suara (menggunakan suara dengan intonasi yang tinggi untuk mengekspresikan kemarahan dan kedengkian terhadap sesorang atau sekelompok orang)
6. Teknik pengambilan gambar. Teknik pengambilan gambar yang sering digunakan dalam film ini yaitu: Close up (untuk menunjukkan pentingnya suatu objek), Medium shot (Untuk menggambarkan pengenalan suatu objek) dan Long shot (untuk menunjukkan hubungan antara subjek dan latar belakang)

7. Sudut pandang pengambilan gambar (angle), yang sering digunakan adalah: Low angle (untuk menunjukkan sifat kekuasaan), High angle (untuk menunjukkan kebalikan dari low angle) dan eye level (untuk menunujukan kesejajaran atau netral)

Film adalah salah satu bentuk media yang memberikan pesan tertentu atas suatu fenomena dalam kehidupan masyarakat. Pesan ini umumnya menggambarkan problematika kehidupan sehari-hari. Dalam film yang berkaitan dengan problematika rasisme ini, sebaiknya pesan yang terkandung memberikan peluang alternatif untuk solusi problematika tersebut. Terdapat banyak peluang bagi peneliti untuk menggunakan analisis ini dalam mengangkat pesan-pesan lainnya yang ada di berbagai film, khususnya film-film yang mencerminkan kehidupan nyata di dalam masyarakat.

\section{DAFTAR PUSTAKA}

Ardianto, E., Komala, L dan Karlinah, S (2014), Komunikasi Massa, Suatu Pengantar. Bandung: Simbiosa Rekatama Media Mulyana, D (2001). Ilmu Komunikasi, Suatu Pengantar. Bandung: Remaja Rosdakarya 
Rakhmat, Jalaludin. 2013. Psikologi

Komunikasi. Bandung: PT. Remaja Rosda Karya

Sobur, Alex. 2004. Semiotika Komunikasi.

Bandung: Remaja Rosdakarya

Zoest, Van. 1993. Semiotika: Tentang Tanda,

Cara Kerjanya dan Apa yang Kita

Lakukan Dengannya. Jakarta: Yayasan Sumber Agung

\section{Internet}

Finley, L.L, and Finley, P.S (2007) Film Review

Essay, The White Supremacist in Anti-
Racist Films, Journal Contemporary

Justice Review, Volume 72004 issue 2, retrieved 10 August 2018

Hughey, M.W, (2011) The White Savior Film and Reviewers' Reception, Symbolic Interaction, Volume 33, Issue 3 2010, retrieved 10 August 2018

Hughey, M.W, (2014) Cinethetic Racism: White Redemption and Black Stereotypes in “Magical Negro” Films, Sosial Problems, Volume 56, Issue 3, 1 Agust 2009, retrived 10 August 2018 